\title{
Research and Implementation of Tractor Power Shift Clutch Control System
}

\author{
Chengjun Li, Meicong Ke and Youyu Wu \\ School of information engineering, Wuhan University of Technology, China
}

\begin{abstract}
Applying power shift control technology on tractor can improve the power, economy and driving comfort of tractor. The separation and engagement control of clutch in tractor power shift transmission system is the key factor to optimize the quality of shift. Through many experiments and tests, an electronic control unit based on MC9S12 was developed, and an effective clutch control strategy was put forward, which improved the jerk of power shift and shortened the gear shift time.
\end{abstract}

\section{Introduction}

The power shift tractor adopts electronic control system to simplify the complicated operation process to simple push-button operation, greatly reducing the driver's control difficulty and labor intensity, and improving the quality of work, so as to improve the work efficiency.

The engaging law of clutch is one of the key technologies of tractor power shift. The automatic clutch is based on the traditional mechanical clutch and is equipped with an electronic control system, which uses modern electronic technology to realize the automation of clutch manipulation. When shifting, the driver presses the shift button, and the clutch automatically completes separation and engagement.

\section{Design of electronic control system}

\subsection{System overall design}

Electronic control unit is the core of the whole control system. Taking MC9S12 as a microcontroller, the information of high and low gear sensors (digital quantities) and clutch travel sensors (analog signals) is extracted and analyzed, data is processed by software, and clutch travel is monitored accurately. According to the feedback information of several sensors, the electro-hydraulic proportional valve and on-off valve are hydraulically controlled, and the engagement speed of the clutch is precisely controlled with proper clutch engagement law. Combined with the clutch travel, the clutch speed is changed in real time, and the movement law of the clutch is effectively controlled so that the gear shift is steady and fast. The hardware system diagram is shown in figure 1 .

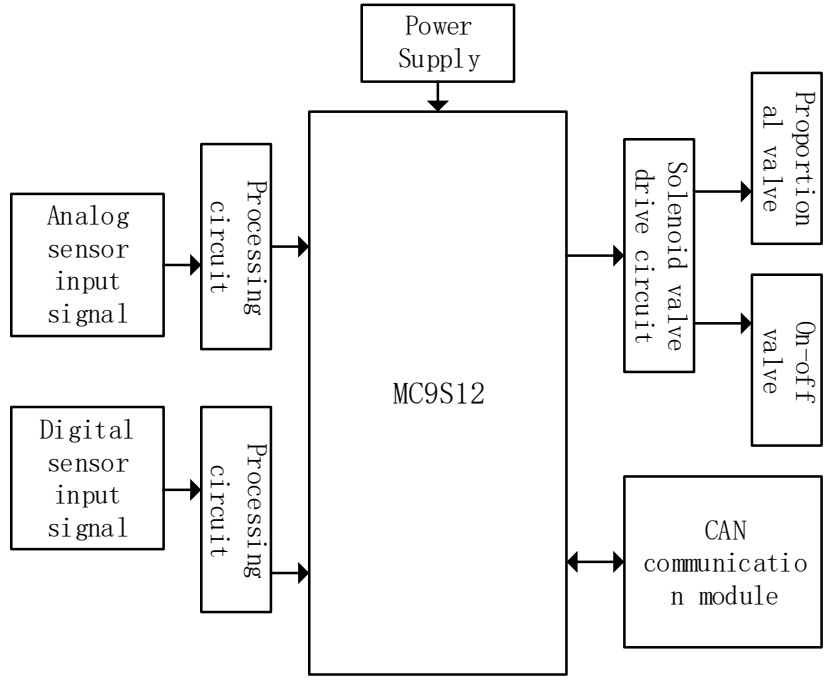

Figure 1. System hardware circuit diagram.

\subsection{Clutch control principle}

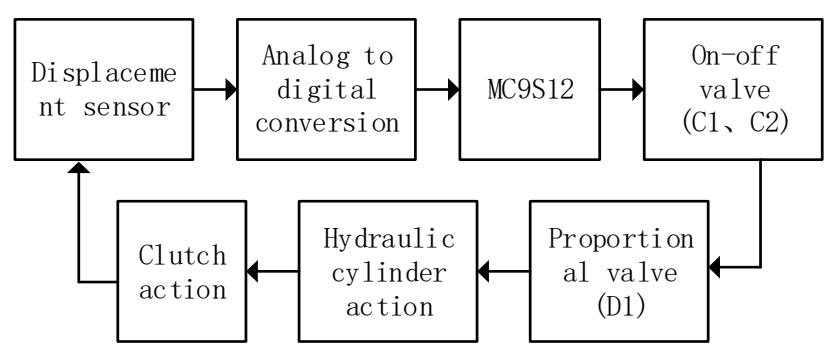

Figure 2. Clutch control schematic.

The action of the clutch is accomplished by the clutch hydraulic cylinder. As shown in figure 2, electronic control system analyzes hydraulic cylinder displacement 
sensor in real-time, through the on-off valve and proportional valve control to achieve the hydraulic cylinder stroke control and speed control, and finally realize the clutch movement control. The physical diagram of the hydraulic cylinder and the displacement sensor is shown in figure 3 .

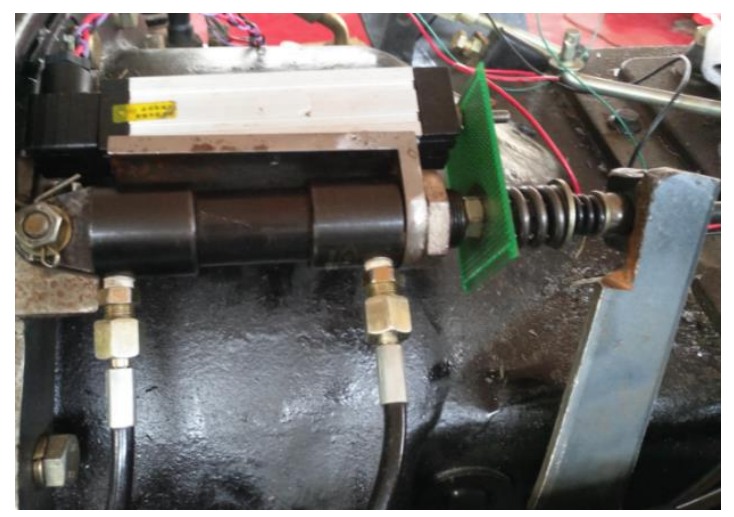

Figure 3. The physical diagram of the hydraulic cylinder and displacement sensor.

\section{Clutch control strategy}

Clutch control strategy determines the quality of shift, and it is the key and difficult point to realize power shift. Through the clutch separation and joint control, it can shorten the shift time, reduce the shift jerk, and improve the shift-feel.

The speed of the engaging or disengaging of the clutch can be realized by the control of the proportional solenoid valve and the on-off valve by the electronic control unit.

Clutch control strategy is divided into two parts: clutch separation control and clutch engagement control.

\subsection{Clutch separation control}

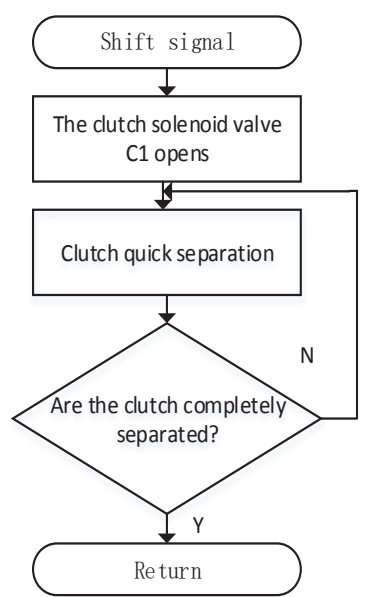

Figure 4. Clutch separation control flow chart.

During the gear shifting process, the power interruption time should be reduced as little as possible in order to avoid excessive power losses which Causes the vehicle speed to fall too much. Therefore. The clutch separation process should be completed quickly.
TCU(Transmission control unit) detects the output signals of each sensor in real time. When the TCU obtains the shift signal, the processor sends out an action instruction to turn on the clutch solenoid valve $\mathrm{C} 1$ so that the hydraulic cylinder rapidly drives the clutch to be rapidly separated. When the TCU obtains that the clutch is completely detached, the TCU closes the clutch solenoid valve $\mathrm{C} 1$, leaving the clutch in a state of separation. See figure 4.

\subsection{Clutch engagement control}

The clutch engagement law directly affects the overall shift quality. The "fast - slow - fast" clutch engagement control strategy can effectively improve the shift quality, referred to as "two fast and one slow".

In the clutch engagement process, the clutch engagement control is divided into three modules, namely, half joint front, half joint point and half joint behind.

The so-called "clutch half joint" means the half linkage. The clutch is engaged, but it is not fully engaged. That is to say, the half joint point is that the vehicle body is about to get enough output torque, and the vehicle body is in a critical state that will not move.

The clutch is rapidly approaching the half joint before the semi junction, which is "one fast". After the half joint, the clutch is quickly and completely engaged to shorten the gear shift time, which is "two fast". At the half joint point, the system controls the flow of the proportional valve so that the clutch engages slowly, ensuring the smoothness of the shift, which is "one slow". So precise control of "two fast and one slow" is the key and difficulty of clutch engagement control.

The total clutch travel is $50 \mathrm{~mm}$.After many experiments and tests, the clutch half joint point is between $30-40 \mathrm{~mm}$. Therefore, in clutch engagement control process, it should be guaranteed that during the travel $30-40 \mathrm{~mm}$, clutch is slowly engaged. The engaging time is about $800 \mathrm{~ms}$. The diagram of clutch travel and speed is shown in figure 5 .

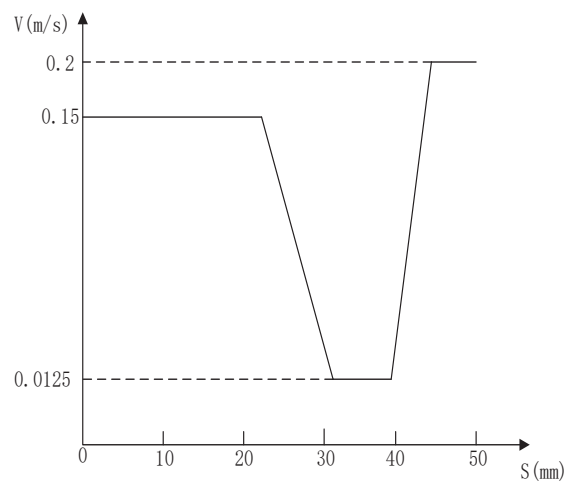

Figure 5. Relationship between clutch engagement speed and stroke.

When the TCU obtains the clutch engagement signal, the TCU sends a control signal to open the clutch solenoid valve $\mathrm{C} 2$, and controls the proportional valve $\mathrm{D} 1$ to output a larger flow, and the clutch engagement speed $v_{1}$ is $0.15 \mathrm{~m} / \mathrm{s}$. At the same time, the analog sensor is 
detecting the clutch travel position, and the TCU processes the acquired analog data by means of software (seeking variance and average value) to obtain the real-time travel of the clutch. When the clutch travel is approaching $30 \mathrm{~mm}$, the TCU sends a control signal to make the proportional solenoid valve D1 output smaller flow, and the clutch engagement speed $v_{2}$ is $0.0125 \mathrm{~m} / \mathrm{s}$; When the clutch travel is measured to be $40 \mathrm{~mm}$, the TCU controls the flow of the proportional valve again, and the clutch engagement speed $v_{3}$ is changed to $0.2 \mathrm{~m} / \mathrm{s}$; When the clutch is detected fully engaged, the TCU closes the solenoid valve $\mathrm{C} 2$ and the proportional valve D1 to complete the engagement of the clutch. The process is shown in figure 6 .

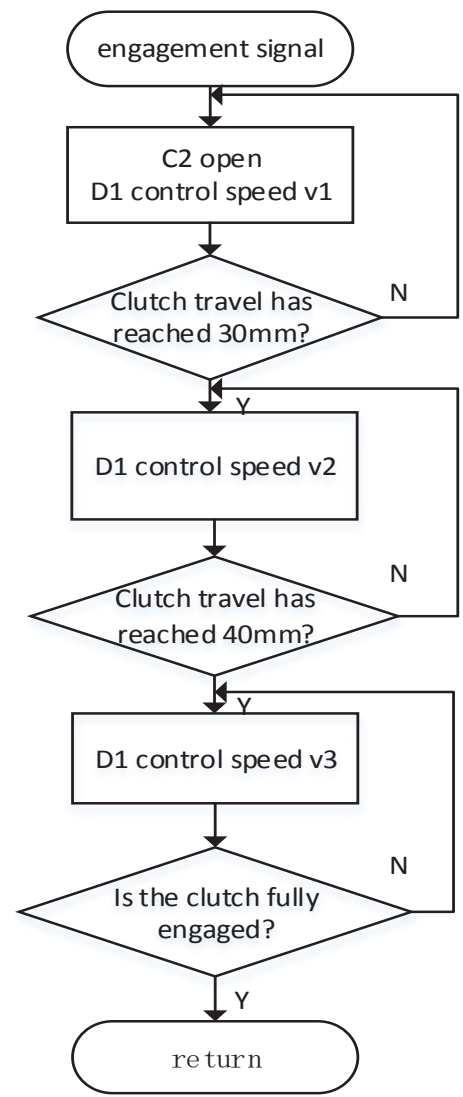

Figure 6. clutch engagement control flow chart.

\section{Experiment analysis}

\subsection{Experimental conditions}

It is necessary to ensure the stability of the hydraulic oil and solenoid valve. Their experimental conditions are shown in table 1 . The whole tractor performance is in good condition, the experimental road is standard leveling cement ground.

Table 1. Experimental conditions

\begin{tabular}{|c|c|}
\hline oil pressure & $12.0 \mathrm{MPa}$ \\
\hline oil temperature & $25-57^{\circ} \mathrm{C}$ \\
\hline solenoid valve $\mathrm{C} 1$ & $25-58^{\circ} \mathrm{C}$ \\
\hline
\end{tabular}

\begin{tabular}{|c|c|}
\hline solenoid valve $\mathrm{C} 2$ & $25-61^{\circ} \mathrm{C}$ \\
\hline proportional valve $\mathrm{D} 1$ & $25-55^{\circ} \mathrm{C}$ \\
\hline
\end{tabular}

\subsection{Experimental evaluation index}

The experiment evaluation index contains two parts: shift jerk $j$ and total shift time $t$.

Shift jerk $j$ is expressed as follows:

$$
j=\frac{d a}{d t}=\frac{d^{2} v}{d t^{2}}
$$

$v$ is tractor speed; $a$ is tractor longitudinal acceleration. The Germany recommended value of jerk is: $j=10 \mathrm{~m} / \mathrm{s}^{3}$; The China recommended value is: $j=17.64 \mathrm{~m} / \mathrm{s}^{3}$.

Total shift time $t$ is expressed as follows:

$$
t=t_{a}+t_{b}+t_{c}
$$

$t_{a}$ is clutch separation time; $t_{b}$ is block time; $t_{c}$ is clutch engagement time;

In order to shorten the total shift time, the clutch separation time can coincide with the block time. Because $t_{a}>t_{b}$, total shift time is

$$
t=t_{a}+t_{c}
$$

As the "two fast and one slow" clutch engagement control strategy, clutch engagement time is divided into three parts:

$$
t_{c}=t_{c 1}+t_{c 2}+t_{c 3}
$$

$t_{c 1}$ is clutch first segment quick engagement time; $t_{c 2}$ is clutch second segment slow engagement time; $t_{c 3}$ is clutch third segment quick engagement time.

Therefore, the total shift time is

$$
t=t_{a}+t_{c 1}+t_{c 2}+t_{c 3}
$$

\subsection{Experimental data analysis}

For the reliability of the data, the following experimental data are collected from two to three gear.

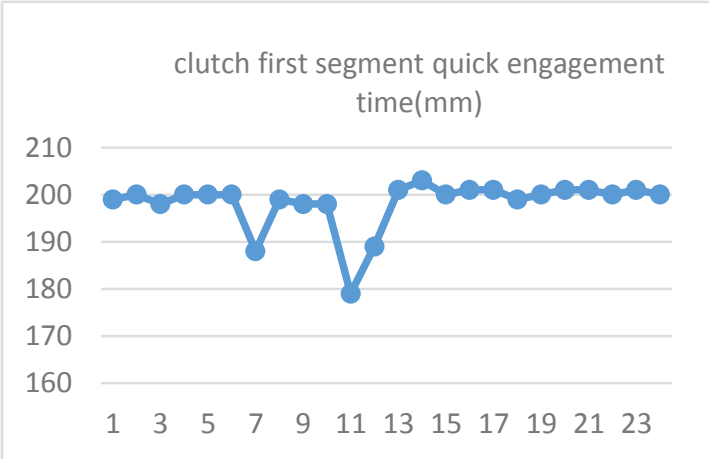

Figure 7. Clutch first segment quick engagement time. 


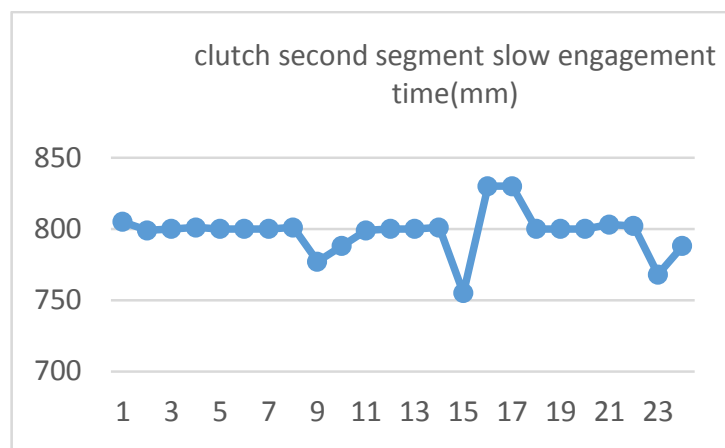

Figure 8. Clutch second segment slow engagement time

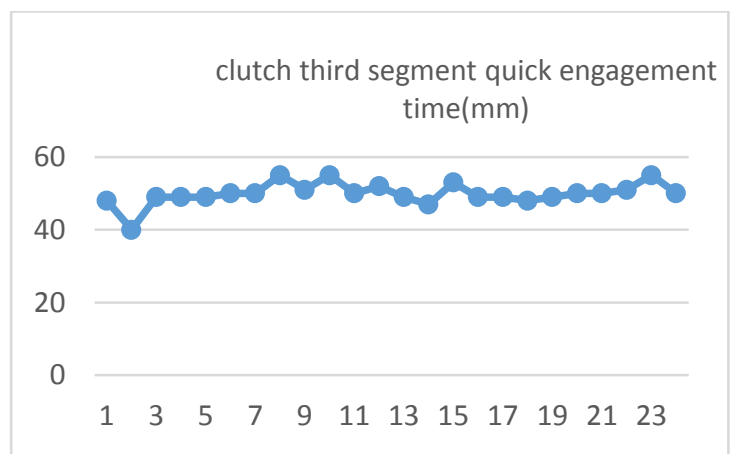

Figure 9. Clutch third segment quick engagement time.

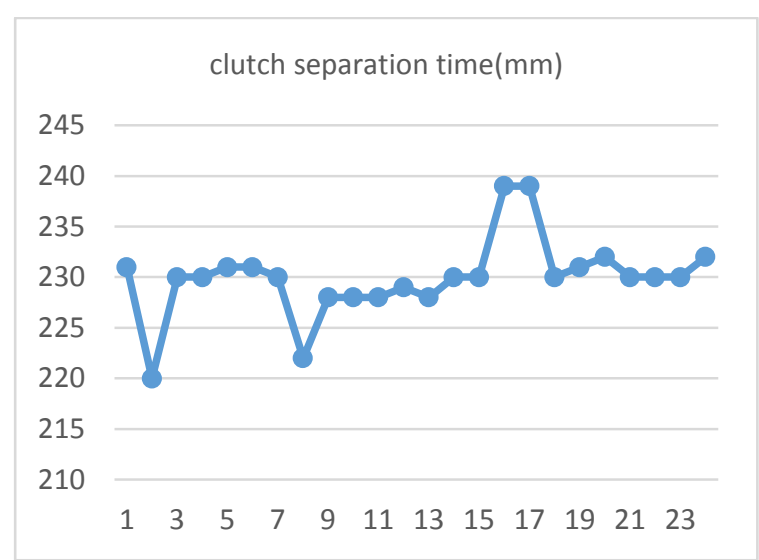

Figure 10. Clutch separation time.

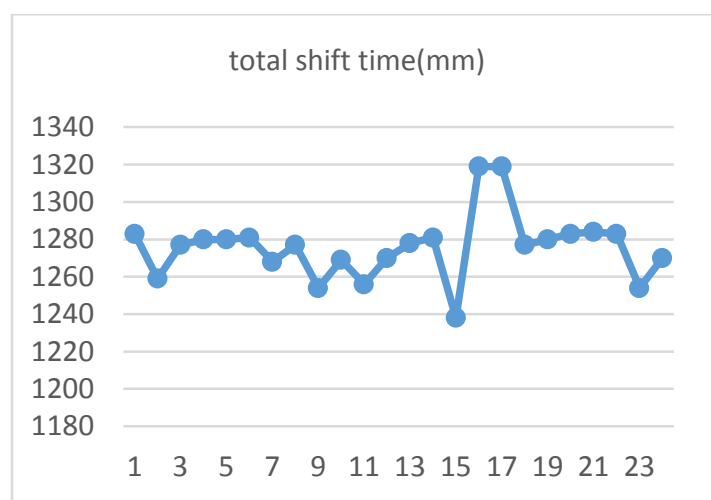

Figure 11. Total shift time.

Fig.7-11 shows the clutch engagement and separation of each part time. The mean value of clutch first segment quick engagement time $t_{c 1}$ is $198.16 \mathrm{~ms}$, the mean value of clutch second segment slow engagement time $t_{c 2}$ is $797.79 \mathrm{~ms}$, the mean value of clutch third segment quick engagement time $t_{c 3}$ is $49.91 \mathrm{~ms}$, the mean value of clutch quick separation time $t_{a}$ is $229.96 \mathrm{~ms}$. So the total shift time is $t 1275.83 \mathrm{~ms}$.

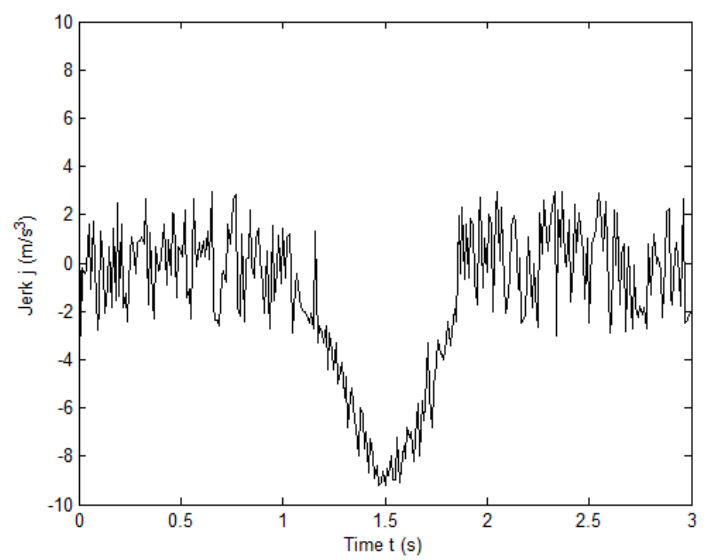

Figure 12. The measured jerk of the gear shift.

Fig.12 is the measured diagram of the jerk of the tractor, and the highest absolute value of the jerk is 9.3 $m / s^{3}$.

The results show that the clutch engagement law adopts the "two fast and one slow" control strategy, which can effectively reduce the shifting sense of frustration and improve the total shift time.

\section{Conclusion}

1) The key problem of tractor power shift technology is put forward, that is, the separation and engagement of clutch.

2) Through many experiments and tests, an electronic control unit based on MC9S12 is developed, and the "two fast and one slow" clutch engagement control strategy is put forward.

3) Through the loading test, the correctness of the "two fast and one slow" clutch control strategy is verified, the total shift time is shortened to $1275.83 \mathrm{~ms}$, and the shift jerk is improved to $9.3 \mathrm{~m} / \mathrm{s}^{3}$.

\section{References}

1. Liu, Jiguo, et al. "Study on Shifting Control Strategy for Tractor AMT System." Agricultural Equipment \& Vehicle Engineering 7(2014).

2. Saitou, Yoshitami, N. Isono, and N. Suzumura. "Electronically controlled clutch engagement speed correcting for an automatic transmission system." US, US5109967. 1992.

3. Ling, Ling, Z. S. Chen, and Y. Y. Luo. "Study on Control Process of Automatic Mechanical Transmission System for Pure Electric Bus."Applied Mechanics \& Materials 220-223(2012):1795-1799.

4. Gao, A., Z. Fu, and W. Zhang. "Fuzzy shift schedule of automatic mechanical transmission for tractors." Transactions of the Chinese Society for Agricultural Machinery 37.11(2006):1-4. 
5. Ota, Atsuo, S. Narita, and T. Masuda. "Shift control unit of electric-power assist transmission." (2000).

6. Nitsche, Martin, and A. Englisch. "Method and apparatus for gear shifting control with improved shift quality during gear shifting." US, US5946984. 1999.
7. Li, Guozheng, and Y. Tan. "Research of automatic gearshift control technology for tractor mechanical gear-box." Journal of China Agricultural University 9.3(2004):85-87. 